\title{
Persepsi Kenyamanan Pejalan Kaki pada Jalur Pedestrian Jalan Gajah Mada Denpasar
}

\author{
I Made Oddie Gupta Wardana ${ }^{1}$, Cokorda Gede Alit Semarajaya ${ }^{1 *}$, Ni Nyoman Ari Mayadewi
}

1. Prodi Arsitektur Lanskap, Fakultas Pertanian, Universitas Udayana, Indonesia, 80236

2. Prodi Agroekoteknologi, Fakultas Pertanian, Universitas Udayana, Indonesia, 80236

*E-mail: coksemarajaya@unud.ac.id

\begin{abstract}
Perceptions of pedestrian convenience on the pedestrian path of Gajah Mada Street Denpasar. Gajah Mada Street as an economic and tourist area requires good and comfortable physical infrastructure to support easy accessibility and circulation of visitors to the area. One of the physical infrastructures is a pedestrian lane which functions as an access to support pedestrian activities. The purpose of this study was to identify the physical conditions of the pedestrian paths and to determine the perception of pedestrian comfort on the pedestrian path at Gajah Mada Street. The research method used in this research is a survey method by performing primary data collection techniques through observation, questionnaires and secondary data through literature study. Based on the research conducted, it is known that there are physical conditions and supporting facilities for the damaged pedestrian paths, in the form of materials and street furniture such as: seats, trash cans and roadside plants. Based on the assessment of perceptional respondents about the condition of pedestrian path has been considered comfortable and safe. The suggestion of this research is that it is necessary to improve the physical condition of the damaged pedestrians. The purpose of improving pedestrian facilities and infrastructure is to facilitate the pedestrians in order to be comfortable and safe in carrying out activities on the pedestrian path.
\end{abstract}

Keywords: pedestrian pathways, physical condition, respondens perception.

\section{Pendahuluan}

Jalan Gajah Mada, Denpasar merupakan jalan yang setiap harinya selalu dipadati dengan berbagai macam aktivitas, salah satunya adalah aktivitas perekonomian yang berada di sepanjang kawasan ini. Aktivitas pasar Badung dan pasar Kumbasari serta kios-kios yang ada di sepanjang kawasan Jalan Gajah Mada menjadikan kawasan ini sebagai salah satu pusat perekonomian yang ada di kota Denpasar. Selain itu kawasan Jalan Gajah Mada merupakan salah satu tempat wisata di kota Denpasar, dengan ciri khas pada bangunan-bangunan kota tuanya yang memiliki nilai historis tentang representasi dari kota tua Denpasar (Entas, 2018). Hal tersebut membuat kawasan ini ditetapkan sebagai kawasan heritage kota Denpasar yang dituangkan dalam Peraturan Daerah (Perda) kota Denpasar No 27 tahun 2011 yang menjadikan kawasan ini sebagai kawasan pusat kegiatan perdagangan, jasa, sosial, budaya, pemerintahan dan kawasan heritage.

Jalan Gajah Mada sebagai kawasan yang padat dengan aktivitas, sepanjang kawasan tersebut diberlakukan larangan parkir kendaraan pada bahu jalan untuk menghindari adanya kemacetan lalu lintas. Kondisi tersebut menjadikan kawasan Jalan Gajah Mada hanya dapat diakses melalui berjalan kaki ketika melakukan aktivitas didalamnya. Dalam menunjang aktivitas tersebut diperlukan adanya fasilitas pejalan kaki sebagai akses yang menghubungkan setiap tempat yang ada di sepanjang kawasan tersebut. Fasilitas bagi pejalan kaki tersebut adalah jalur pedestrian, dimana jalur pedestrian yang aman, nyaman, dan manusiawi merupakan hal penting yang harus disediakan untuk menunjang mobilitas bagi pejalan kaki pada kawasan Jalan Gajah Mada Denpasar (Permen PU No 3 Tahun 2014).

Pada saat ini Jalan Gajah Mada telah dilengkapi dengan jalur pedestrian. Namun saat ini kondisi jalur pedestrian Jalan Gajah Mada masih ditemukan berbagai macam penyalahgunaan fungsi jalur pedestrian yang terjadi yaitu: parkir kendaraan pada jalur pedestrian, jalur pedestrian sebagai tempat meletakkan barang dagangan toko serta sebagai tempat berdagang. Terdapat pula peletakan street furniture seperti pot tanaman yang membuat ruang pada jalur pedestrian menjadi berkurang. Sehingga jalur pedestrian Jalan Gajah Mada tidak dapat digunakan secara maksimal oleh pejalan kaki yang seharusnya jalur pedestrian tersebut memberikan pelayanan yang optimal kepada pejalan kaki dari segi keamanan dan kenyamanan. Berdasarkan 
latar belakang di atas maka perlu dilakukan studi terhadap kondisi jalur pedestrian dan persepsi pengguna untuk mengetahui kenyamanan pejalan kaki pada jalur pedestrian Jalan Gajah Mada, Denpasar. Hasil penelitian ini dapat dijadikan sebagai rekomendasi dalam peningkatan kualitas jalur pedestrian di Jalan Gajah Mada, Denpasar.

\section{Metode Penelitian}

\subsection{Waktu dan Lokasi}

Penelitian ini dilakukan pada jalur pedestrian di kawasan Jalan Gajah Mada, Denpasar, Bali dengan panjang Jalur pedestrian 730 meter. Penelitian ini dilakukan selama 9 bulan, yakni dari bulan Februari 2020 hingga November 2020.

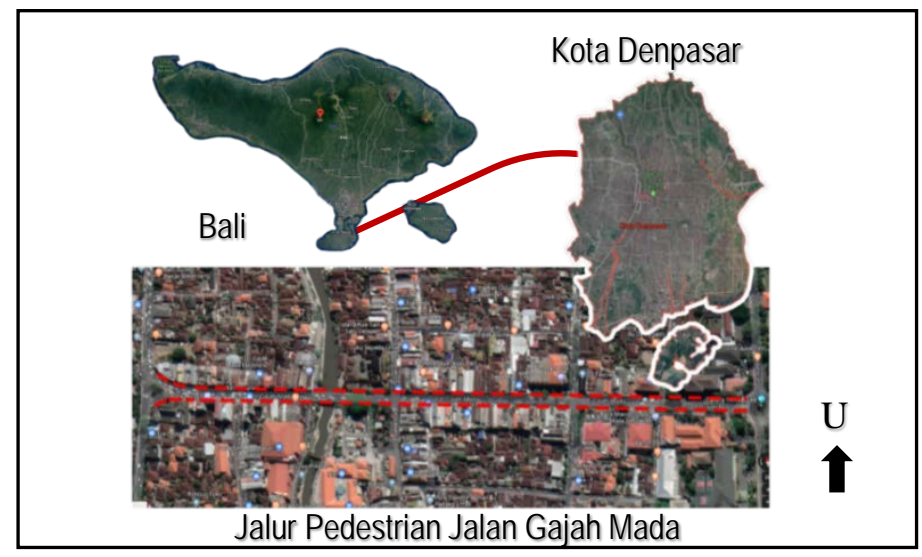

Gambar 1. Lokasi Penelitian

(Sumber: Google Earth, 2020)

\subsection{Alat dan Bahan}

Alat yang digunakan pada penelitian ini yaitu Alat tulis, Lembar kuesioner, Laptop, Software Microsoft Word, Microsoft Excel, Google Earth, Adobe Photoshop CS6, GPS, Kamera. Sedangkan bahan yang digunakan dalam penelitian ini adalah peta lokasi penelitian.

\subsection{Metode Penelitian}

Metode penelitian yang digunakan dalam penelitian ini adalah metode survei dengan melakukan teknik pengumpulan data primer melalui observasi, kuesioner dan data sekunder melalui studi pustaka. Observasi dilakukan guna memperoleh data mengenai kondisi fisik jalur pedestrian Jalan Gajah Mada Denpasar. Kuesioner digunakan dengan tujuan untuk memperoleh informasi mengenai persepsi keamanan dan kenyamanan pejalan kaki terhadap jalur pedestrian Jalan Gajah Mada, Denpasar dengan jumlah responden sebanyak 30 orang. Jenis kuesioner yang digunakan adalah kuesioner tertutup dengan teknik sampling yang digunakan yaitu purposive random sampling. Penyebaran kuesioner dilakukan selama satu minggu, yakni tanggal 20 hingga 26 Februari 2020 pada pukul 09.00-21.00 Wita. Waktu tersebut menjadi acuan dalam penyebaran kuesioner dikarenakan pada waktu tersebut jalur pedestrian aktif digunakan.

\subsection{Batasan Penelitian}

Lokasi penelitian dilakukan pada Jalur Pedestrian Jalan Gajah Mada, Denpasar. Penelitian ini dibatasi pada aspek persepsi kenyamanan pejalan kaki sebagai pengguna terhadap kondisi jalur pedestrian Jalan Gajah Mada Denpasar.

\section{Hasil dan Pembahasan}

\subsection{Gambaran Umum Lokasi Penelitian}

Jalan Gajah Mada terletak di Desa Dauh Puri Kangin, Kecamatan Denpasar Timur, Kota Denpasar, Bali. Jalan Gajah Mada merupakan kawasan pusat kegiatan perdagangan, jasa, sosial, budaya, pemerintahan dan kawasan heritage. Membentang dari ujung barat berbatasan dengan jalan Thamrin hingga ujung timur pada patung Catur Muka sepanjang 730 meter yang di lengkapi dengan jalur pedestrian pada kedua sisinya yaitu 
sisi utara dan selatan. Jalur pedestrian Jalan Gajah Mada dilengkapi fasilitas pendukung jalur pedestrian seperti: rambu dan marka, tempat duduk, drainase, telepon umum, lampu penerangan, pelindung/peneduh, jalur hijau. Penggunaan jalur pedestrian beragam selain fungsi khusus jalur sebagai jalur pejalan kaki, terdapat aktivitas lain di dalamnya diantaranya: bersosialisasi, perdagangan, keindahan kota, bersantai dan juga beristirahat.

\subsection{Aksesibilitas dan Sirkulasi}

Jalur Pedestrian memiliki beberapa permasalahan mengenai aksesibilitas dan sirkulasi, dimana aksesibilitas dan sirkulasi didalamnya terganggu akibat kondisi jalur pedestrian yang terputus, aktivitas parkir kendaraan pada jalur pedestrian dan aktivitas perdagangan.

\subsection{Dimensi Jalur Pedestrian}

Data yang diperoleh melalui survei dan pengukuran langsung di lapangan jalur pedestrian Jalan Gajah Mada memiliki lebar jalur pedestrian beragam antara 1,5 m hingga 6,8 $\mathrm{m}$. Ketinggian pembatas antara jalan dengan jalur pedestrian telah memenuhi standar maksimal ketinggian yaitu kanstin dengan ketinggian $20 \mathrm{~cm}$.

Beberapa titik jalur pedestrian Jalan Gajah Mada memiliki ukuran lebar yang relatif sempit diakibatkan oleh peletakan street furniture (prabot jalan) pada jalur pedestrian seperti pot tanaman, bantaran lampu jalan dan bantaran patung di area pedestrian, bahkan terdapat jalur pedestrian yang hanya memiliki lebar $30 \mathrm{~cm}$. berikut merupakan kondisi street furniture yang menghalangi jalur pedestrian, dapat dilihat pada Gambar 2.
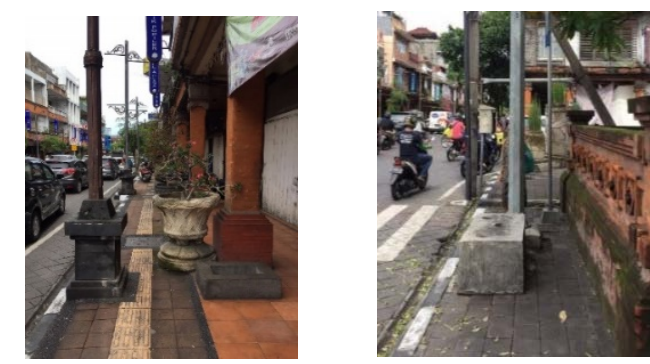

Gambar 2. Street Furniture Menghalangi jalur Pedestrian

\subsection{Material jalur pedestrian}

Standar penggunaan jenis material untuk sarana dan prasarana jaringan pejalan kaki adalah menggunakan material yang mampu menyerap air, tidak menyilaukan, perawatan yang murah dan tidak licin. Berdasarkan hasil observasi ditemukan permasalahan terkait dengan kondisi material jalur pedestrian.

a. Kerusakan struktur

Kerusakan struktur tersebut meliputi permukaan paving yang berlubang hingga terlepas. Kerusakan struktur juga terjadi pada guiding block di sepanjang jalur pedestrian yang dalam keadaan rusak dan terputus yang dapat membahayakan pengguna dengan keterbatasan fisik (3a).

b. Inkonsistensi penggunaan material

Penggunaan material yang tidak konsisten seperti penggunaan batu sikat dan penutup besi sebagai penutup jalur pedestrian. Penggunaan batu sikat dan besi berlubang untuk material jalur pedestrian dapat membahayakan dan mencelakai pejalan kaki (3b).
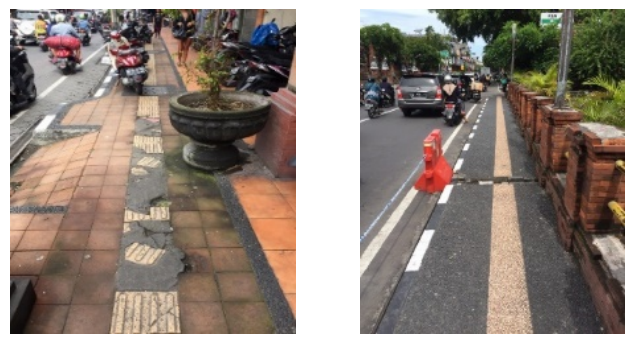

\subsection{Street furniture}

Gambar 3. Kerusakan Struktur (a), Inkonsistensi Penggunaan Material (b)

Berikut merupakan street furniture yang terdapat pada jalur pedestrian Jalan Gajah Mada yaitu: rambu dan marka, drainase, lampu penerangan, jalur hijau. 
a. Rambu dan marka

Rambu yang terdapat pada jalur pedestrian Jalan Gajah Mada yaitu rambu penyeberangan, rambu larangan parkir, dan rambu petunjuk arah. Marka pada jalur pedestrian untuk fasilitas pejalan kaki adalah marka melintang sebagai marka penyeberangan yang berupa zebra cross. Area penyeberangan pada jalur pedestrian yaitu area penyeberangan yang kurang aksesibel bagi pejalan kaki karena terdapat penempatan street furniture pada akses penyeberangan yang menghalangi pejalan kaki. Berikut merupakan kondisi street furniture yang menghalangi jalur masuk zebra cross, dapat dilihat pada Gambar 4.

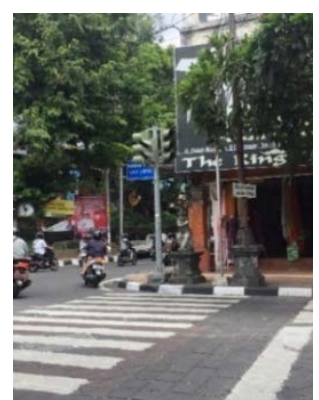

Gambar 4. Street Furniture Menghalangi Jalur Masuk

\section{b. Penerangan}

Sebanyak 27 buah lampu penerangan dengan kondisi yang mati. Kondisi tersebut dapat berpotensi menimbulkan terjadinya tindakan kriminal dan tidak terlihatnya jalur pedestrian sehingga membahayakan pejalan kaki serta menimbulkan rasa tidak aman dan nyaman saat bermobilisasi (5a). Selain itu kondisi kabel yang terbuka dan bergantungan pada area pedestrian dapat membahayakan keamanan pejalan kaki (5b).
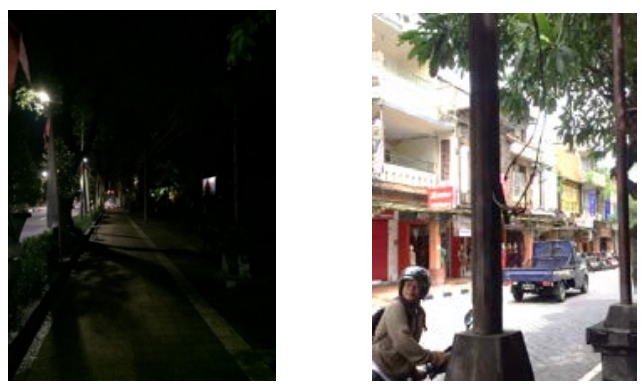

Gambar 5. Kondisi Lampu Penerangan Mati (a), Kabel Terbuka dan Bergelantungan (b)

\section{c. Drainase}

Kondisi drainase pada jalur pedestrian tergolong dalam kondisi yang baik. Pada observasi yang dilakukan drainase dapat menjadi jalur untuk pembuangan air dengan baik.

d. Tanaman tepi jalan

Penanganan yang tepat perlu dilakukan terhadap tanaman tepi jalan untuk mendapatkan fungsi secara maksimal. Hasil observasi yang dilakukan tanaman tepi jalan dapat berpotensi menjadi penghalang bagi pejalan kaki jika tidak dilakukan perawatan yang intensif. Berikut merupakan kondisi tanaman pada jalur pedestrian, dapat dilihat pada Gambar 6.
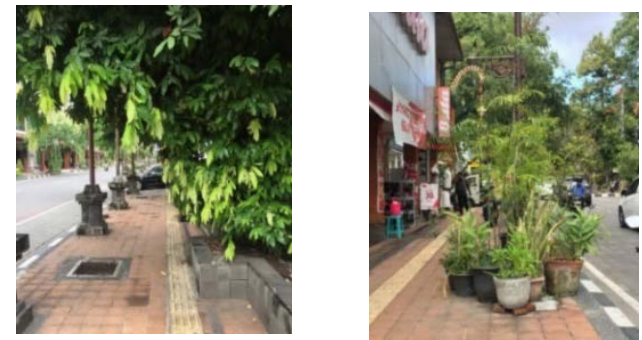

Gambar 6. Kondisi Tanaman 


\subsection{Keindahan jalur pedestrian}

Keindahan harus dirancang dengan memperhatikan dari berbagai segi, baik itu segi bentuk, warna, komposisi susunan tanaman dan elemen perkerasan, serta diperhatikan juga faktor-faktor pendukung sirkulasi kegiatan manusia. (Hakim dan Utomo dalam Anggriani, 2009)

Segi bentuk Fasade bangunan yang berada di sepanjang jalur pedestrian memiliki rupa dan bentuk dengan satu kesatuan yang sama dengan ciri bangunan pecinan dengan perpaduan antara arsitektur Tionghoa, Belanda dan Bali (Yusiana, 2016). Demikian halnya dengan street furniture seperti lampu penerangan, plang nama toko dan bangku taman didesain dengan gaya dan warna yang mewakili karakter lokal lingkungan Jalan Gajah Mada. Namun kondisi beberapa bangunan di sepanjang jalur pedestrian Jalan Gajah Mada terdapat kondisi kabel-kabel bergantungan pada sepanjang bangunan yang berantakan sehingga menyebabkan berkurangnya keindahan dari bangunan-bangunan tersebut dan terkesan kumuh. Kurangnya perawatan pada tanaman pada sepanjang jalur pedestrian mengakibatkan beberapa tanaman dalam kondisi mati dan berantakan. Selain kondisi tersebut keberadaan tanaman liar yang berada pada jalur pedestrian menyebabkan berkurangnya nilai estetika. Berikut merupakan kondisi keindahan jalur pedestrian, dapat dilihat pada Gambar 7.

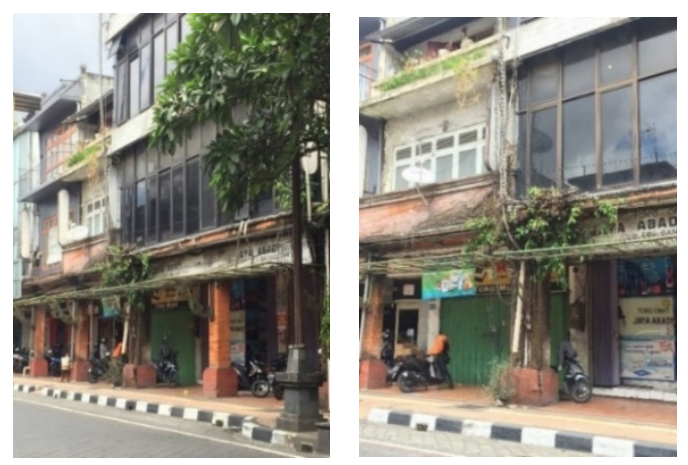

Gambar 7. Kondisi Keindahan Jalur Pedestrian

\subsection{Karakteristik Responden}

Karakteristik responden berdasarkan jenis kelamin yaitu 60\% laki-laki dan 40\% responden dengan jenis kelamin perempuan. Persentase usia responden didominasi oleh usia 17-25 Tahun dengan nilai 87\%. Responden dengan usia 26-35 Tahun 7\%. Responden dengan usia 36-45 Tahun 3\% dan lansia usia >56 Tahun dengan nilai persentase $3 \%$.

Latar belakang pendidikan responden didominasi oleh tingkatan perguruan tinggi dengan persentase $50 \%$ dan pada tingkatan SMA dengan persentase $47 \%$ dan tingkat pendidikan SD dengan persentase $3 \%$. Dominasi pekerjaan utama responden yang ditemui adalah siswa/ mahasiswa dengan persentase $67 \%$, pegawai swasta dengan persentase $20 \%$, tidak bekerja dengan persentase $10 \%$ dan wiraswasta dengan persentase $3 \%$.

Sebagian besar responden melakukan kunjungan pada waktu siang hari dengan nilai persentase tertinggi yaitu $43 \%$. Aktivitas responden yang dominan pada siang hari tersebut dikarenakan toko-toko yang berada di sepanjang jalur pedestrian Jalan Gajah Mada telah beroperasi secara keseluruhan pada siang hari.

Kunjungan responden pada jalur pedestrian hanya dilakukan sesekali dengan persentase tertinggi yaitu $67 \%$. Hal ini disebabkan aktivitas yang dilakukan di Jalur Pedestrian Jalan Gajah Mada tidak intens dilakukan. Aktivitas utama responden adalah melakukan perbelanjaan yang hanya dilakukan saat diperlukan.

\subsection{Persepsi responden}

Persepsi responden terhadap kenyamanan jalur pedestrian Jalan Gajah Mada, Denpasar menggunakan indikator kondisi kenyamanan dan keamanan. Indikator kondisi kenyamanan menggunakan indikator kondisi fisik jalur pedestrian berupa dimensi jalur pedestrian, bahan atau material jalur pedestrian, street furniture dan faktor lain yang mempengaruhi kenyamanan yaitu: sirkulasi, iklim, kebisingan, aroma atau bau-bauan, keamanan dan keindahan. Indikator keamanan terpisah dari parameter kenyamanan dikarenakan keamanan 
merupakan masalah yang tidak sederhana, sehingga perlu dilakukan pembedaan untuk menghasilkan informasi yang lebih lengkap. Berikut merupakan analisis mengenai persepsi kenyamanan dan keamanan pejalan kaki pada jalur pedestrian Jalan Gajah Mada, Denpasar:

Tabel 1. Tabel Penilaian Kenyamanan Responden

\begin{tabular}{|c|c|c|c|c|c|c|c|c|}
\hline No & Kriteria Penilaian & STN & TN & CN & $\mathrm{N}$ & SN & $\begin{array}{l}\text { Jumla } \\
\text { h Skor }\end{array}$ & $\begin{array}{l}\text { Rata } \\
\text {-rata }\end{array}$ \\
\hline 1 & $\begin{array}{l}\text { Kemudahan aksesibilitas dan } \\
\text { sirkulasi }\end{array}$ & - & $53 \%$ & $30 \%$ & $17 \%$ & - & 264 & 2,64 \\
\hline 2 & Lebar jalur pedestrian & $7 \%$ & $43 \%$ & $40 \%$ & $10 \%$ & - & 253 & 2,53 \\
\hline 3 & Tinggi jalur pedestrian & - & $30 \%$ & $53 \%$ & $17 \%$ & - & 287 & 2,87 \\
\hline 4 & $\begin{array}{l}\text { Bahan atau material jalur } \\
\text { pedestrian }\end{array}$ & $3 \%$ & $57 \%$ & $30 \%$ & $7 \%$ & $3 \%$ & 250 & 2,50 \\
\hline 5 & Keberadaan rambu dan marka & $3 \%$ & $17 \%$ & $60 \%$ & $20 \%$ & - & 297 & 2,97 \\
\hline 6 & Drainase & $3 \%$ & $13 \%$ & $67 \%$ & $10 \%$ & $7 \%$ & 305 & 3,05 \\
\hline 7 & Lampu penerangan & $3 \%$ & $33 \%$ & $57 \%$ & $7 \%$ & - & 268 & 2,68 \\
\hline 8 & Drainase & $3 \%$ & $13 \%$ & $67 \%$ & $10 \%$ & $7 \%$ & 305 & 3,05 \\
\hline 9 & Lampu penerangan & $3 \%$ & $33 \%$ & $57 \%$ & $7 \%$ & - & 268 & 2,68 \\
\hline 10 & Tanaman tepi jalan & $17 \%$ & $40 \%$ & $13 \%$ & $30 \%$ & - & 250 & 2,50 \\
\hline 11 & Kebersihan area pedestrian & $3 \%$ & $53 \%$ & $17 \%$ & $27 \%$ & - & 268 & 2,68 \\
\hline 12 & Aroma atau bau-bauan & $7 \%$ & $27 \%$ & $50 \%$ & $13 \%$ & $3 \%$ & 278 & 2,78 \\
\hline 13 & Keindahan jalur pedestrian & $3 \%$ & $23 \%$ & $40 \%$ & $27 \%$ & $7 \%$ & 312 & 3,12 \\
\hline \multirow[t]{2}{*}{14} & Suara atau kebisingan & $27 \%$ & $37 \%$ & $27 \%$ & $7 \%$ & $3 \%$ & 225 & 2,25 \\
\hline & Rerata & $6 \%$ & $34 \%$ & $43 \%$ & $15 \%$ & $2 \%$ & 273 & 2,73 \\
\hline
\end{tabular}

Tabel 2. Tabel Penilaian Keamanan Responden

\begin{tabular}{|c|c|c|c|c|c|c|c|c|}
\hline No & Kriteria Penilaian & STA & TA & $\mathrm{CA}$ & $A$ & SA & $\begin{array}{l}\text { Jumlah } \\
\text { Skor }\end{array}$ & $\begin{array}{l}\text { Rata- } \\
\text { rata }\end{array}$ \\
\hline 1 & $\begin{array}{l}\text { Keamanan aksesibilitas dan } \\
\text { sirkulasi di jalur pedestrian }\end{array}$ & - & $53 \%$ & $37 \%$ & $10 \%$ & - & 130 & 1,30 \\
\hline 2 & Lebar jalur pedestrian & - & $80 \%$ & $10 \%$ & $7 \%$ & $3 \%$ & 233 & 2,33 \\
\hline 3 & Tinggi jalur pedestrian & $3 \%$ & $13 \%$ & $67 \%$ & $10 \%$ & $7 \%$ & 305 & 3,05 \\
\hline 4 & $\begin{array}{l}\text { Bahan atau material jalur } \\
\text { pedestrian }\end{array}$ & - & $67 \%$ & $13 \%$ & $17 \%$ & $3 \%$ & 256 & 2,56 \\
\hline 5 & $\begin{array}{l}\text { Lokasi zebra cross (tempat } \\
\text { penyeberangan) }\end{array}$ & $3 \%$ & $13 \%$ & $50 \%$ & $27 \%$ & $7 \%$ & 322 & 3,22 \\
\hline 6 & Penerangan jalur pedestrian & - & $17 \%$ & $60 \%$ & $23 \%$ & - & 306 & 3,06 \\
\hline \multirow[t]{2}{*}{7} & Tanaman tepi jalan & $7 \%$ & $20 \%$ & $57 \%$ & $13 \%$ & $3 \%$ & 285 & 2,85 \\
\hline & Rerata & $2 \%$ & $38 \%$ & $42 \%$ & $15 \%$ & $3 \%$ & 262 & 2,62 \\
\hline
\end{tabular}

Berikut merupakan hasil analisis mengenai persepsi kenyamanan dan keamanan pejalan kaki pada jalur pedestrian Jalan Gajah Mada, Denpasar.

1. Aksesibilitas dan Sirkulasi

Penilaian tertinggi responden mengenai persepsi keamanan dan kenyamanan menyatakan tidak nyaman (TN) dengan persentase 53\% dan tidak aman (TA) dengan persentase 53\%. Penilaian responden tersebut didukung dengan hasil analisis yang didapatkan yaitu: pedestrian yang terputus, parkir kendaraan pada jalur pedestrian dan keberadaan pedagang pada area pedestrian. Sehingga menyebabkan pengguna menjadi tidak nyaman dan tidak aman dikarenakan harus berbagi dengan aktivitas lainnya saat bermobiliasi. 
2. Dimensi jalur pedestrian

Penilaian dimensi pada jalur pedestrian meliputi tinggi dan lebar dari jalur pedestrian. Berikut merupakan persentase kenyamanan dan keamanan mengenai dimensi jalur pedestrian Jalan Gajah Mada, Denpasar:

a. Tinggi jalur pedestrian

Persentase penilaian tertinggi responden mengenai keamanan dan kenyamanan tinggi jalur pedestrian yaitu, 53\% menyatakan cukup nyaman (CN) dan 67\% menyatakan cukup aman (CA). Respon yang diberikan oleh responden sesuai dengan hasil analisis yang didapatkan yaitu, ketinggian jalur pedestrian telah sesuai standar maksimum ketinggian jalur pedestrian yaitu $20 \mathrm{~cm}$ dari permukaan jalan.

b. Lebar jalur pedestrian

Persentase penilaian tertinggi dari kondisi kenyamanan dan keamanan mengenai lebar jalur pedestrian adalah 43\% menyatakan tidak nyaman (TN) dan 80\% menyatakan tidak aman (TA). Penilaian responden tersebut didukung dengan analisis yang didapatkan mengenai lebar pedestrian. Peletakan street furniture dan terdapat aktivitas seperti parkir dan berdagang mengakibatkan berkurangnya ruang pejalan kaki

3. Bahan atau material jalur pedestrian

Persentase penilaian tertinggi dari kondisi kenyamanan dan keamanan bahan atau material menurut responden dengan kategori tidak nyaman (TN) dengan persentase 57\% dan tidak aman (TA) dengan persentase $67 \%$. Dari hasil analisis yang dilakukan material jalur pedestrian mengalami kerusakan di sepanjang jalurnya. Kerusakan struktur yang terjadi yaitu permukaan paving yang berlubang hingga lepas, genangan air pada permukaan jalur pedestrian, rusaknya guiding blocks, penggunaan material licin dan penggunaan penutup jalur pedestrian yang kurang aksesibel bagi pejalan kaki. Keutuhan jalur pedestrian menjadi poin terpenting dari keselamatan pejalan kaki, karena hal tersebut menyangkut keselamatan pengguna pedestrian (Sa'adah, 2018).

4. Street furniture

Berikut merupakan penilaian persepsi responden mengenai street furniture yang terdapat pada jalur pedestrian Jalan Gajah Mada, Denpasar:

a. Rambu dan marka

Keberadaan rambu dan marka jalan dinilai cukup nyaman (CN) oleh responden dengan nilai persentase $60 \%$. Berdasarkan analisis yang dilakukan kondisi rambu dan marka pada jalur pedestrian telah sesuai dengan kebutuhan pejalan kaki dan dapat dengan mudah dilihat yang menjadikan rambu dan marka mampu memberikan informasi yang baik pada pejalan kaki.

b. Drainase

Persentase hasil penilaian tertinggi responden terhadap kenyamanan drainase sebanyak $67 \%$ responden menyatakan cukup nyaman (CN). Penilaian responden didukung dengan kondisi drainase di sepanjang jalur pedestrian yang memiliki keadaan yang baik dan tidak menyebabkan terjadinya genangan air.

c. Lampu penerangan

Persentase tertinggi responden terhadap kenyamanan dan keamanan lampu penerangan menyatakan cukup nyaman (CN) dengan persentase $57 \%$ dan cukup aman (CA) dengan persentase $60 \%$. Penilaian responden yang menyatakan kondisi cukup nyaman dan cukup aman tersebut dilatar belakangi oleh dominan responden melakukan aktivitasnya pada siang hari, sehingga memungkinkan responden tidak mengetahui kondisi penerangan jalur pedestrian saat malam hari. Penilaian responden tersebut berbanding terbalik dengan hasil analisis yang ditemukan, kondisi penerangan jalur pedestrian banyak dalam keadaan mati dan gelap. Selain itu kondisi kabel pada tiang lampu penerangan yang terbuka dapat membahayakan pejalan kaki.

d. Tanaman tepi jalan

Persentase tertinggi responden mengenai kenyamanan tanaman tepi jalan sepanjang jalur pedestrian adalah 40\% menyatakan tidak nyaman (TN). Penilaian responden tersebut sesuai dengan hasil analisis ditemukan kondisi tanaman yang kurang terawat serta terdapat tanaman hingga masuk ke jalur pedestrian sehingga mengakibatkan pejalan kaki menjadi tidak nyaman dalam bermobilisasi

Persentase tertinggi menurut responden mengenai keamanan tanaman tepi jalan di sepanjang jalur pedestrian $57 \%$ menyatakan cukup aman (CA). Berdasarkan hasil analisis yang dilakukan tidak ditemukan kondisi tanaman tepi jalan yang membahayakan bagi pejalan kaki. Kondisi tersebut menjadi faktor penilaian positif responden terhadap tanaman tepi jalan di jalur pedestrian Jalan Gajah Mada Denpasar. 


\section{Kebersihan jalur pedestrian}

Kebersihan jalur pedestrian mendapatkan penilaian tidak nyaman (TN) dengan persentase $53 \%$. Penilaian tidak nyaman responden tersebut sesuai dengan hasil analisis yang didapatkan dilapangan yaitu keberadaan sampah pada jalur pedestrian masih sering dijumpai pada semak-semak di antara tanaman.

6. Aroma atau bau-bauan

Hasil persentase tertinggi dari kondisi kenyamanan mengenai aroma atau bau-bauan di sepanjang jalur pedestrian dinilai cukup nyaman (CN) dengan persentase $50 \%$. Penilaian cukup nyaman oleh responden didukung dengan hasil analisis yang didapatkan yaitu tidak ditemukannya aroma atau bau-bauan yang tidak sedap di sepanjang jalur pedestrian.

7. Keindahan jalur pedestrian

Hasil persentase tertinggi dari kondisi kenyamanan mengenai keindahan jalur pedestrian dinilai cukup nyaman (CN) dengan persentase 40\%. Keindahan lanskap jalur pedestrian Jalan Gajah Mada menjadi daya tarik tersendiri, dimana kondisi lanskap kuno pada sepanjang jalur pedestrian memberikan kesan yang berbeda bagi masyarakat.

8. Suara atau kebisingan

Hasil persentase tertinggi dari kondisi kenyamanan mengenai suara atau kebisingan di sepanjang jalur pedestrian dinilai tidak nyaman (TN) dengan persentase tertinggi yaitu 37\%. Penilaian tidak nyaman oleh responden didukung dengan hasil analisis yang didapatkan dilapangan, yaitu letak jalur pedestrian yang bersebelahan dengan kendaraan bermotor. Kondisi tersebut mengakibatkan kebisingan yang diakibatkan dari suara kendaraan bermotor yang lalu-lalang.

\subsection{Sintesis dan Rekomendasi}

Sintesis merupakan tahapan akhir berupa pencarian solusi terhadap permasalahan yang diuraikan sebelumnya. Berikut merupakan sintesis dan rekomendasi yang dihasilkan berdasarkan permasalahan yang diuraikan sebelumnya:

1. Aksesibilitas dan sirkulasi

a. Terputusnya jalur pedestrian

Menyambung jalur pedestrian yang terputus dan mengatur pelandaian pada jalan masuk jalur pedestrian. Hal ini bertujuan agar mobilisasi menjadi jelas dan lancar sehingga pejalan kaki tidak kebingungan dalam melakukan mobilisasi. Berikut merupakan rekomendasi pengaturan pelandaian jalan masuk direkomendasikan menggunakan pelandaian jalan masuk dan kerb kombinasi, dapat dilihat pada Gambar 8.

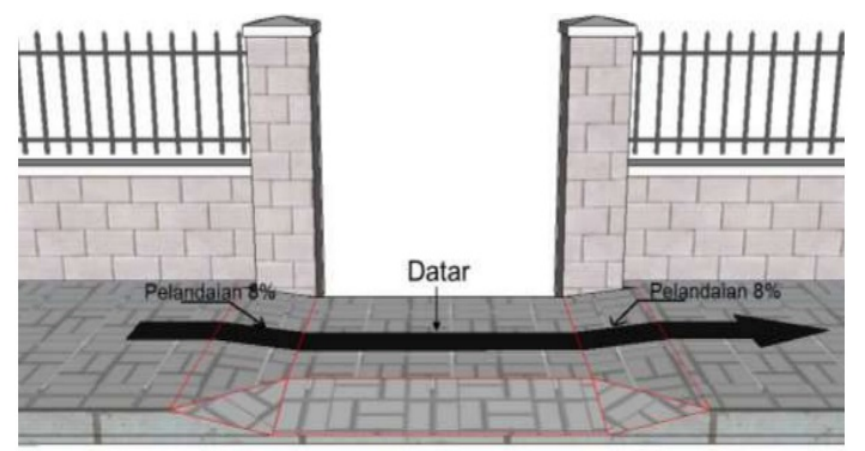

Gambar 8. Model pengaturan jalan masuk jalur pedestrian

(Sumber: SE Mentri PUPR N0. 2 Tahun 2018)

b. Parkir kendaraan pada jalur pedestrian

Pentertiban terhadap kendaraan parkir di atas jalur pedestrian agar tidak menganggu mobilisasi pejalan kaki. Parkir kendaraan disarankan pada sentral parkir pasar badung yang dapat digunakan sebagai tempat parkir kendaraan.

c. Keberadaan pedagang pada jalur pedestrian

Melakukan penertiban terhadap pedagang yang menggunakan pedestrian sebagai tempat untuk berdagang. 


\section{Dimensi Jalur pedestrian}

Lebar efektif minimum jaringan pejalan kaki berdasarkan kebutuhan dua orang berjalan tanpa membawa barang minimal memiliki lebar $150 \mathrm{~cm}$. Kondisi jalur pedestrian yang memiliki ukuran lebar jalur yang beragam menjadi permasalahan yang dialami pada kawasan Jalan Gajah Mada Denpasar. Kondisi tersebut mengakibatkan pejalan kaki menjadi tidak nyaman dalam bermobilisasi, sehingga direkomendasikan untuk memaksimalkan penggunaan jalur pedestrian lama (teras toko) sebagai jalur pejalan kaki. Hal tersebut diharapkan menjadi solusi dalam menambah ruang bagi pejalan kaki di Kawasan Jalan Gajah Mada, Denpasar.

3. Material jalur pedestrian

a. Kerusakan struktur

Mengganti material jalur pedestrian yang rusak menggunakan bahan dan material yang sesuai dengan standar. Menurut standar penggunaan material jalur pedestrian yaitu mampu menyerap air, tidak menyilaukan, perawatan yang mudah dan tidak licin (9a). Mengganti material penutup jalur pedestrian yang menggunakan penutup besi berlubang dengan menggunakan media beton atau besi tertutup sebagai penutup jalur pedestrian agar tidak membahayakan pejalan kaki saat melakukan mobilisasi (9b)
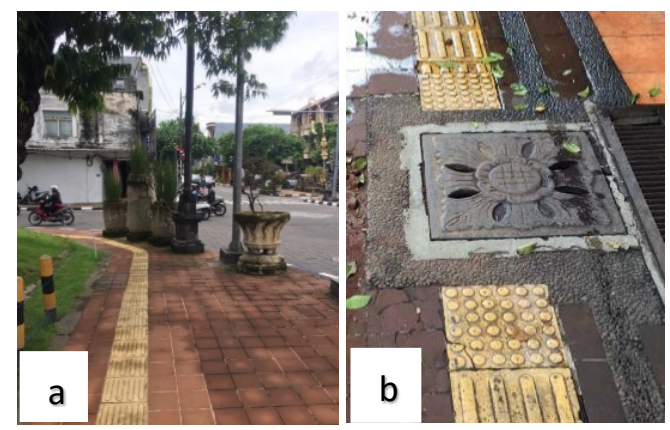

Gambar 9. Model material jalur pedestrian(a), Model Penutup Jalur Pedestrian (b)

\section{Street furniture}

a. Melakukan penataan terhadap penempatan street furniture

Penempatan street furniture agar memperhatikan kriteria lebar ruas pada jaringan pejalan kaki agar tidak mengganggu fungsi utamanya sebagai ruang pejalan kaki dan tidak mengurangi dimensi jalur pedestrian.

b. Melakukan perbaikan lampu penerangan di sepanjang jalur pedestrian.

Kondisi lampu penerangan jalur pedestrian sebanyak 27 buah dengan kondisi yang mati. Kondisi tersebut dapat menjadi penyebab terjadinya tindakan kriminal dan kecelakaan akibat tidak terlihatnya jalur pedestrian. Perlu dilakukan perbaikan terhadap lampu penerangan yang mengalami kerusakan serta perawatan terhadap lampu penerangan disepanjang jalur pedestrian agar pejalan kaki merasa nyaman dan aman.

c. Tanaman tepi jalan

Perawatan secara intensif perlu dilakukan agar tanaman dapat berfungsi secara maksimal. Tanaman tepi jalan sangat bermanfaat bagi iklim mikro, Tanaman dapat sebagai pengontrol radiasi sinar matahari dan suhu dengan menyerap panas dari pancaran sinar matahari dan memantulkannya sehingga dapat menurunkan suhu dan iklim mikro (Iswanto, 2006). Kondisi tanaman yang kurang terawat menyebabkan fungsi dari tanaman sebagai buffering untuk dapat mengurangi kebisingan juga menjadi tidak maksimal. Penanaman jenis tanaman (pohon, perdu/semak) yang mempunyai tajuk yang tebal dan bermasa daun padat efektif untuk meredam suara, seperti: tanjung, kiara payung, teh-tehan, puring, pucuk merah, kembang sepatu dan bougenville (Peraturan Menteri PU No 5 Tahun 2012). Selain itu akibat tidak terawatnya tanaman pada jalur pedestrian mengakibatkan keindahan lanskap jalan menjadi berkurang bahkan kondisi tersebut dapat mengganggu dan membahayakan mobilisasi.

\section{Simpulan dan Saran \\ 4.1 Simpulan}

Berdasarkan hasil analis data dan sintesis yang telah dilakukan dalam penelitian, disimpulkan bahwa: 
1. Kondisi fisik jalur pedestrian Jalan Gajah Mada sepanjang 730 meter dengan kondisi fisik yang tidak nyaman dan membahayakan bagi pejalan kaki. Hasil yang didapatkan kondisi jalur pedestrian tidak mampu memberikan kelancaran, keamanan dan kenyamanan bagi pejalan kaki. Hal tersebut dapat dilihat dari sebagian besar kondisi fisik jalur pedestrian dalam keadaan rusak dan tidak sesuai dengan perencanaan teknis fasilitas pejalan kaki menurut SE Mentri PUPR No. 2 Tahun 2018 diantaranya material jalur pedestrian, dimensi jalur pedestrian, dan street furniture seperti: lampu penerangan dan tanaman tepi jalan.

2. Persepsi kenyamanan dan keamanan responden terhadap jalur pedestrian Jalan Gajah Mada Denpasar dinilai cukup nyaman dan aman oleh responden. Berdasarkan hasil penilaian responden terhadap kondisi ketinggian jalur pedestrian, keberadaan rambu dan marka, drainase, lampu penerangan, aroma atau baubauan dan keindahan jalur pedestrian dinilai cukup nyaman bagi mayoritas responden. Persepsi tersebut dipengaruhi pula oleh karakteristik responden yang melakukan mobilisasi pada jalur pedestrian, waktu dan frekuensi mobilisasi responden menjadi faktor yang mengakibatkan penilaian cukup nyaman dan aman responden.

\subsection{Saran}

Perlu adanya perhatian pemerintah dalam hal ini untuk melakukan perbaikan terhadap kondisi fisik jalur pedestrian yang mengalami kerusakan, melakukan peningkatan sarana dan prasarana pejalan kaki untuk dapat memfasilitasi pejalan kaki agar dapat nyaman dan aman dalam melakukan aktivitas di jalur pedestrian.

\section{Daftar Pustaka}

Anggriani, N. (2009). Pedestrian Ways Dalam Perancangan Kota. Klaten: Yayasan Humaniora.

Entas, D. (2018). Kawasan Heritage Jalan Gajah Mada Sebagai Upaya Pelestarian Kawasan Kota Tua Denpasar Bali. Jurnal Industri Pariwisata 1(1): 13-19.

Iswanto, D. (2006). Pengaruh Elemen-elemen Pelengkap Jalur Pedestrian Terhadap Kenyamanan Pejalan Kaki. http://eprints.undip.ac.id/18474/1/4 _danoe_ielemen_lanskap_pandanaran.pdf. (Diakses pada 12 November 2019)

Republik Indonesia. Peraturan Mentri Pekerjaan Umum Nomor 5 tahun 2012 Tentang Pedoman Penanaman Pohon Pada Sistem Jaringan jalan.

Republik Indonesia. Peraturan Mentri Pekerjaan Umum Nomor 3 Tahun 2014 Tentang Pedoman Perencanaan Penyediaan dan Pemanfaatan Prasarana dan Sarana Jaringan Pejalan Kaki di Perkotaan.

Republik Indonesia. Surat Edaran Menteri PUPR Nomo 2 Tahun 2018 Tentang Pencanaan Teknis Fasilitas Pejalan Kaki.

Muslihun, M. (2013). Studi Kenyamanan Jalur Pejalan Kaki Terhadap Pemanfaatan Jalur Pedestrian di Jalan Protokol Kota Semarang. Skripsi (tidak dipublikasikan) Universitas Negri Semarang. Semarang.

Pemerintah Kota Denpasar. Peraturan Daerah Kota Denpasar No 27 Tahun 2011 Tentang Rencana Tata Ruang Wilayah Kota Denpasar Tahun 2011 - 2031.

Sa'adah, T.M. (2018). Persepsi dan Preferensi Kenyamanan Pejalan Kaki Tunanetra Terhadap Jalur Pedestrian di Jalan Pang Lima Besar Sudirman, Kota Denpasar. E-Jurnal Arsitektur Lanskap. 4(1): 6573.

Yusiana, L.S. (2016). Konsep Interpretasi Guna Melestarikan Tapak Sejarah di Pecinan Jalan Gajah Mada, Denpasar. E-Jurnal Arsitektur Lanskap. 2(2): 165-176. 